\title{
On species delimitation: Yet another lemur species or just genetic variation?
}

Matthias Markolf ${ }^{1 *}$, Markus Brameier ${ }^{2}$ and Peter M Kappeler ${ }^{1,3}$

\begin{abstract}
Background: Although most taxonomists agree that species are independently evolving metapopulation lineages that should be delimited with several kinds of data, the taxonomic practice in Malagasy primates (Lemuriformes) looks quite different. Several recently described lemur species are based solely on evidence of genetic distance and diagnostic characters of mitochondrial DNA sequences sampled from a few individuals per location. Here we explore the validity of this procedure for species delimitation in lemurs using published sequence data.

Results: We show that genetic distance estimates and Population Aggregation Analysis (PAA) are inappropriate for species delimitation in this group of primates. Intra- and interspecific genetic distances overlapped in 14 of 17 cases independent of the genetic marker used. A simulation of a fictive taxonomic study indicated that for the mitochondrial D-loop the minimum required number of individuals sampled per location is 10 in order to avoid false positives via PAA.

Conclusions: Genetic distances estimates and PAA alone should not be used for species delimitation in lemurs. Instead, several nuclear and sex-specific loci should be considered and combined with other data sets from morphology, ecology or behavior. Independent of the data source, sampling should be done in a way to ensure a quantitative comparison of intra- and interspecific variation of the taxa in question. The results of our study also indicate that several of the recently described lemur species should be reevaluated with additional data and that the number of good species among the currently known taxa is probably lower than currently assumed.
\end{abstract}

\section{Background}

Species are the fundamental units of evolutionary biology as they define the entities that are studied and compared in every field of biology [1]. Moreover, they are the currency for biodiversity classification of geographic regions, and are therefore used to define regions of conservation priority, so-called biological hotspots $[2,3]$. Despite the central importance of species, there is no general agreement about what a species is, and the 'species problem' is one of the most discussed topics in evolutionary biology [4-6].

An overview of species concepts is beyond the scope of this article, but it should be emphasized that the discussion has shifted away from the philosophical and conceptual questions towards a more pragmatic approach in recent years [7,8]. De Quieroz [1] argued

\footnotetext{
* Correspondence: mmarkol@gwdg.de

'Behavioral Ecology and Sociobiology Unit, German Primate Center, Kellnerweg 4, 37077 Göttingen, Germany

Full list of author information is available at the end of the article
}

that all modern species definitions are variations on the same general linage concept of species, because these definitions equate species either explicitly or implicitly with segments of population level evolutionary lineages [1,9-11].

Adopting a concept of species as population level lineages will not solve the problems related to species delimitation in practice, but there would no longer be a discussion of the species concept [1]. In doing so, the concept of species and the question how we recognize a species in practice are encapsulated [12], which means that no single property is necessary to be considered crucial, as is reproductive isolation for the Biological Species Concept (BSC) or a phylogenetically distinct cluster for the Phylogenetic Species Concept (PSC), because every single criterion is likely to fail or to yield ambiguous results $[6,11,13]$. As empahasized by Ernst Mayr [14], species should therefore be delimited with different datasets (criteria) [3,10,15-19]. In practice,
C Biomed Central 
morphological and molecular approaches are mutually informative [20] and often feasible.

The recent taxonomic practice in the primates of Madagascar (Lemuriformes) looks quite different for the most part. Tattersall [21] recently questioned whether the dramatic increase of recognized lemur species in recent years is due to previously unnoticed cryptic diversity or to taxonomic inflation. In 1982, he counted 36 lemur species, whereas in 2007 already 83 species were recognized. This is an increase of 1.88 lemur species per year over 25 years, which is partly due to the fact that small, nocturnal animals were actually being captured for the first time, that research effort has increased, that remote forests have been visited and that new molecular techniques have become available. In 2011, the count is currently at 101 species [22], which means that the rate of new species descriptions more than doubled (to 4.5 species per year) in the last 5 years alone. Are we still unraveling cryptic taxonomic diversity or has the use of particular methods or criteria kindled taxonomic inflation? Because Tattersall's question seemed to have been largely ignored, we re-visit this problem, using quantitative genetic methods to scrutinize methods and concepts used to describe new lemur taxa.

It is particularly striking that several recent taxonomic studies of lemurs are based almost exclusively on evidence from mitochondrial DNA (but see [23-28]. Even where morphometric data were available, they were not analyzed statistically [29-31]. Specifically, a relatively small number of individuals per location were typically sampled in formerly uninvestigated areas. Mitochondrial DNA was then sequenced and compared with previously published data. If the sampled individuals clustered together in a phylogenetic tree and interspecific genetic distances between the new and other taxa were in the range of previous published interspecific distances within the genus under study, and if additional diagnostic sites could be determined via Population Aggregation Analysis (PAA) [32], a new species was proposed and eventually described.

Genetic distances are valid tools for taxonomy because sequences of different organizational levels (e.g. within species, within genera, within families) exhibit different amounts of divergence, which do not overlap and create a gap [33]. This gap can be used as an objective threshold for a species boundary. One indispensable prerequisite for this procedure is to calculate genetic distances at both levels of organization (within and between species) in order to identify the gap. This was often not the case in lemurs (e.g. see [29-31]). For example, comparisons of intraspecific levels of divergence for populations of Microcebus [34] and Lepilemur [35] were based on as few as 3 individuals ( $M$. bongolavenesis), but it is not known whether this is sufficient for a representative characterization of the existing intraspecific variation. Similarly, [36] divergence estimates of the D-loop of $3.7 \%$ between $M$. margotmarshae and $M$. mamiratra were used in identifying the former as a new species. This approach needs to be reconciled with the observation of Fredsted et al. [37], who found genetic divergences of up to $8.2 \%$ among potentially interbreeding individuals of Microcebus murinus within an area of 3 $\mathrm{km}^{2}$ of continuous forest. In light of these overlapping levels of genetic variance within and between taxa, the question arises on which criteria species delimitations should be based and which sample sizes are likely to be sufficient to identify true differences.

The problem of an appropriate sample size is also relevant for PAA, a method frequently used to support inferences about the existence of new taxa in combination with the PSC (e.g. [30,31,34-36]). PAA compares homologous sequences drawn from different populations. A position (base in DNA sequence) that is fixed (i.e. fully conserved) in one population, but has a different state (base) compared to another population is treated as diagnostic site or character. Although it is known that PAA is prone to small sample sizes [38,39], we also asked how PAA would be influenced by sample size, using a simulation with data from a real population of Microcebus, a genus with particularly many recently described new species.

The aims of this study were, therefore, to use the publicly available information about genetic variation from different lemur taxa to identify typical levels of intra- and interspecific genetic variation at loci commonly used in species delimitation and to determine minimal reliable sample sizes for these types of analyses. It is explicitly not our intention to single out particular studies for criticism. We know from personal experience that field work in Madagascar can be extremely difficult, that some species live at low densities and or high up in the canopy, making access to a desirable number of samples very difficult. We also realize (but do personally not endorse) the view that sacrificing potentially rare animals for proper description and deposition in an accessible museum is ethically challenging for some; a fact that may also contribute to false positives and an inflation of species numbers. Finally, it can also be argued that assigning species status to a potentially endangered taxon is a politically justified strategy in order to achieve maximal preemptive conservation effects because extinction cannot be reversed. This approach will also favor splitting over lumping and contribute to an increase in species numbers. All these aspects and problems at the interface of sound scientific procedures, practical difficulties of fieldwork and conservation politics can benefit from sound empirical criteria, which we hope to contribute with these analyses. 


\section{Results}

\section{Genetic distances}

Intra- and interspecific genetic distances are plotted pair-wise for each taxon and marker in Figure 1. Only the genetic distances of Lepilemur for the tRNA marker, the Microcebus distances for the PAST fragment [40] and the cytochrome B distances for Mirza show no overlap. All other pair-wise plots show more or less overlap of intra- and interspecific genetic distances. In several cases the smallest interspecific value even exceeds the lower level of intraspecific variation. None of the different markers show a superior performance over different genera. Lepilemur and Microcebus exhibit the highest intra- and interspecific variation for all markers.

\section{PAA Simulation}

The simulation of diagnostic characters (Figure 2) revealed that two individuals drawn from a population lead to 11-12 diagnostic sites that would argue for a separation into two species. The curve describing the relationship between sample size and the number of diagnostic sites drops relatively fast. However, 10 individuals randomly drawn from each population can still occasionally lead to the identification of a diagnostic character as the curve has not reached 0 yet. What is

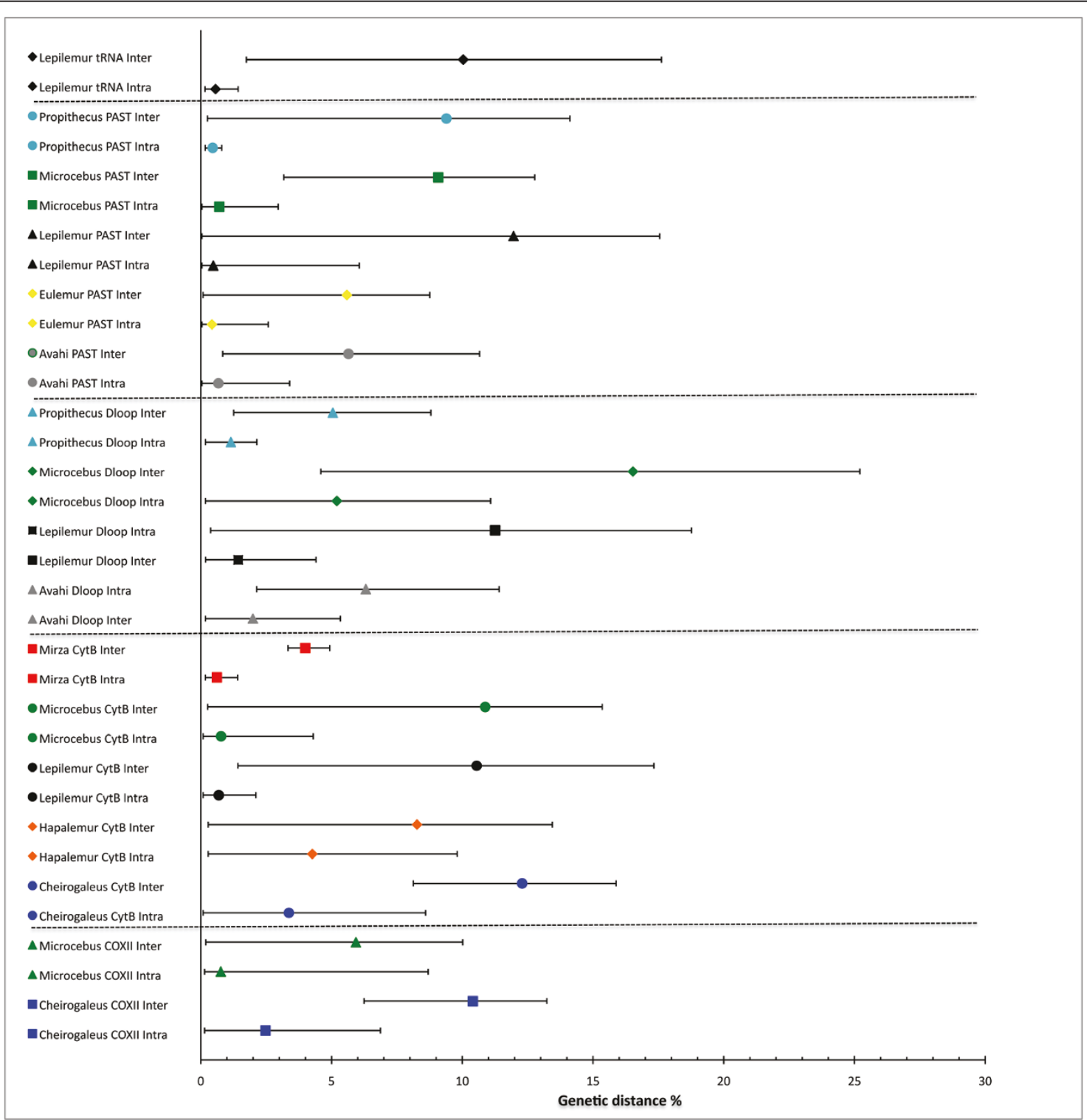

Figure 1 Genetic distance plot. $x$ - axis = Genetic distance in \%; $y$ - axis = lemur genera and analyzed marker with unique identifier. Interspecific distances per taxa are plotted above intraspecific. Plots are grouped by marker. 




Figure 2 Plot of mean diagnostic characters per sample size. $X$ axis = samples drawn from each population, $Y$-axis = diagnostic characters (a site in a DNA sequence of a population that has a fixed but different state as in another population), CS7 = Population 1, CS5N5 = Population 2, males = blue, females = red; 2, 4, 6, .., 20 Individuals were randomly drawn 10,000 times.

also evident is that sampling only females is much more likely to produce diagnostic sites than sampling only males. Random sampling of 8 females per population still results in one diagnostic character, on average, arguing for separation into two species according to the PSC.

\section{Discussion}

\section{Genetic distance}

The comparison of intra- and interspecific distances across several lemur genera and markers revealed that none of the commonly used markers are generally suitable for distance-based species delimitation in this taxon. One possible error in our estimation could be the wrong assignment of an individual to a certain species, because of changing taxonomy. However, we checked affiliation several times in all cases and used the most recent publication referring to the sequence in question.

The overlap of intra- and interspecific distances in most cases is best explained by paraphyly and polyphyly of the mitochondrial DNA [41] of the relevant taxa. For example, the overlap of Avahi distance estimates for the D-loop and PAST fragment is due to paraphyly of Avahi peyriasi [29,42]. Three types of Avahi peyriasi are distinguished. The fact that all of them actually occur at one site (Ranomafana) indicates that the taxonomy of the south-eastern Avahi taxa (A. peyrierasi, A. betsileo, $A$. ramanantsoavanai, $A$, meridionalis) is highly questionable and should be revised.

The same problem applies to Eulemur fulvus, which was also paraphyletic for the PAST fragment [40]. Hapalemur aloatrensis is not distinguishable from Hapalemur griseus on a molecular basis. This, and the paraphyly of Hapalemur griseus subspecies, leads to the observed overlap in cytochrome B $[43,44]$. Interspecific distances of Lepilemur (D-loop; PAST) are as small as the lower limit of intraspecific distances. Zinner et al. [45] already questioned the existence of L. mittermeieri and L. tymerlachsonorum. Where intraspecific divergence reaches high levels, e.g. 8\% in Microcebus for COX II, we can expect that more species are going to be described if this locus is being used. Indeed, these $8 \%$ are caused by individuals from Bemanasy, which seem to form an independently evolving linage [25].

Another factor influencing the overlap of intra- and interspecific distances might be the geographical distribution of different taxa. Whereas some taxa like $M$. murinus are widespread (but see Weisrock et al. 2010), others, such as $M$. tavaratra occur only in very restricted areas [22].

Whatever the explanation for the overlap of intra and interspecific distances in different taxa, the present analysis indicates that a constant "threshold species delimitation", as it is used in barcoding approaches, cannot be recommended [46].

\section{PAA simulation}

For the present simulation, we used as diagnostic characters only those sites that are fixed and different between populations. Sites that are variable within populations, but different between populations are sometimes also referred to as being diagnostic attributes $[47,48]$, and would lead to an even higher number of diagnostic characters.

Our simulation showed that sampling fewer than 10 individuals can falsely lead to diagnostic characters and to an argument for identifying a new species under the PSC. The number of published diagnostics characters for several recently newly described lemur species for the mitochondrial D-loop are far below 10 (e.g. [29]). Because this analysis was focused on the highly variable mitochondrial D-loop, this value should not be used as a general guideline for taxonomic sampling. For less polymorphic markers, such as cytochrome b for example, the curve would probably need fewer individuals to reach zero. However, to establish a general sampling threshold the same analysis ought to be repeated for several different markers and populations. Walsh [38] estimated necessary sampling values of > 50 individuals in order to perform well with PAA. Wiens and Servidio [39] even argued that hundreds and thousands of individuals would be necessary to identify diagnostic characters that are valid for the species boundary. This is unpractical and impossible for most taxonomic studies, however. Hence, other species delimitation methods should be favored and are discussed below. 
Finally, the simulation revealed a clear difference between males and females. Because of its uniparental inheritance and male-biased dispersal in Microcebus, mitochondrial DNA exhibits necessarily higher divergence between populations [49]. That does not mean that there is no genetic exchange via males, however. Gene flow is an important feature of species, especially in introgressed species. Therefore, genetic markers with high levels of gene flow in the dispersing sex should be more effective for species delimitation [50].

\section{How to delimit species?}

We have argued that sole analysis of uniparentally inherited genomes, like mtDNA, is not sufficient to delimit species, as it does not realistically reflect the population history [41]. On the other hand, sequencing other parts of the genome revealed that gene trees can differ substantially between different loci [51-54] because each locus has its own evolutionary history [55]. These differences between loci can challenge the delimitation of species via nuclear DNA, but can also be used to draw inferences about population size and subdivision, gene flow and hybridization [53], all of which play a role in generating new taxa and biodiversity. The use of multiple loci including nuclear and sex-specific markers in studying the evolutionary history of populations has already been applied in several other organsims [51,55-58] apart from lemurs (for exceptions see [23-25]), and is highly recommended to obtain a realistic picture of the population history [59] and to adequately describe phylogenies at and below the species level [60]. Recent advances in sequencing technology provide the possibility for multilocus analyses, even of non-model species (for lemurs see [61]). The use of multilocus sequence data requires different statistical procedures, which become more and more sophisticated. Likelihood and Bayesian summary statistics are now commonly used in phylogeographic and phylogenetic inference and replace older methods that rely on single gene trees $[62,63]$.

Using Bayesian structure analysis [64] and the Genealogical Sorting Index (GSI) [65] Weisrock et al. [25] confirmed the high number of Microcebus species using several nuclear markers, although species were not reciprocally monophyletic. In contrast, using also several nuclear markers in combination with morphological data, Groeneveld et al. [23,24] reduced the number of Cheirogaleus species from 7 to 4 , indicating the suitability to delimit species with several types of information [3,10,15-18,66-68]. For example, morphologically distinct mouse lemurs [26] could be comfirmed as separate species with genetic data [27]. Similarly, Zimmermann [69] and Nietsch [70] have emphasized the suitability of vocalizations for species delimitation in non-human primates, and this type of data has been used to clarify the taxonomy of tarsiers, for example [71]. Whatever these data might be, genetic samples, morphological measurements or other types of data should be sampled in a way that intraspecific variation can be assessed and compared to interspecific variation before new species are described.

Why lemur taxonomists have not used the abovementioned criteria to delimit species is only speculative, but one reason might have been that collecting high quality samples for DNA analyses from many individuals is anything but easy. Furthermore, the methods to extract nuclear DNA from low quality samples such as fecal or museum samples and sequencing those at low costs as well as nuclear primers were only recently developed [61]. Finally, from a conservation perspective, the urgent need to protect several highly threatened areas in Madagascar may have favored splitting species over lumping as well.

\section{Conclusions}

We conclude that PAA and genetic distances are inappropriate singular methods to delimit lemur species. Furthermore, we encourage the use of several nuclear and sex-specific genetic loci as well as the combination of different datasets for species delimitation. Populations that are considered to be different species should be sampled in a way that intraspecific variation can be compared with interspecific variation. Recently described lemur species should be critically re-evaluated, and we predict a taxonomic deflation for several genera.

\section{Methods}

\section{Genetic distances}

We searched the NCBI database for published lemur sequences and downloaded those in the application Geneious Pro (version 4.8.5). Sequences were grouped by genus and sub-grouped by sequenced loci. Taxonomic identity of each sequence was either based on the publication or on locality, if taxonomy was likely to have changed over years. Sequences were aligned using the ClustalW plugin in Geneious and afterwards checked by eye. Distances were estimated using the software MEGA [72]. We calculated p-distances, as it is the mostly used method in previous lemur publications and report distances as percentage genetic distances. Gaps or different length of sequences were not used for calculations as we chose the pair-wise deletion option in MEGA.

We calculated genetic distances within species (intraspecific) and between species (interspecific). Values were exported to Excel to process and to visualize distances. Afterwards we plotted the mean and the range to the lowest and highest value of intra- and interspecific distances per marker and taxon. 


\section{Simulation}

To simulate the impact of sample size to the results of PAA on the number of species, we used one of the best-studied mouse lemur population at Kirindy Forest. The published dataset consists of 202 different gray mouse lemur individuals (Microcebus murinus), which showed 22 haplotypes for the mitochondrial D-loop [37]. All sequences were aligned and cut to equal length (529bp) The gray mouse lemur population at Kirindy showed significant genetic structure between 3 local study sites (CS5, CS7 and N5), which are 2-3 km apart (see Fredsted et al. [37] for details of the study area). This substructure was used for the simulation as different sampling areas for a fictive taxonomic study. We divided the population into two sampling areas (CS5 and N5 vs CS7), including approximately the same number of individuals in each population.

Afterwards 2, 4, 6, ...20 sequences were drawn randomly from each population 10,000 times for the entire dataset and for males and females separately. After each step the number of diagnostic characters were determined and the mean was plotted against the number of sequences drawn from each population. Simulations were done using PERL (PERL script can be received by request from the authors).

\section{Acknowledgements}

We thank the Ministére d'Eaux et Forêt of Madagascar and the Département Biologie Animale of the University of Madagascar for their continued authorization and support of our field work in Kirindy and elsewhere in Madagascar. Thanks to two anonymous referees for helpful comments on an earlier version of this manuscript.

\section{Author details}

${ }^{1}$ Behavioral Ecology and Sociobiology Unit, German Primate Center, Kellnerweg 4, 37077 Göttingen, Germany. ²Department of Primate Genetics, German Primate Center, Kellnerweg 4, 37077 Göttingen, Germany. ${ }^{3}$ Department of Sociobiology/Anthropology, University of Göttingen, Kellnerweg 6, 37077 Göttingen, Germany.

\section{Authors' contributions}

MM and PMK conceived the study and wrote the paper. MM and MB analyzed data and conducted the simulation. All authors have read and approved the final manuscript.

\section{Competing interests}

The authors declare that they have no competing interests.

Received: 5 May 2011 Accepted: 21 July 2011 Published: 21 July 2011

\section{References}

1. de Queiroz K: The general lineage concept of species, species criteria, and the process of speciation. In Endless Forms: Species and Speciation. Edited by: Howard D, Berlocher S. Oxford: Oxford University Press; 1998:

2. Agapow P, Bininda-Emonds O, Crandall K, Gittleman J, Mace G, Marshall J, Purvis A: The impact of species concept on biodiversity studies. $Q$ Rev Biol 2004, 79:161-179.

3. Balakrishnan R: Species Concepts, Species Boundaries and Species Identification: A View from the Tropics. Syst Biol 2005, 54:689-693.

4. Coyne JA, Orr HA: Speciation Sunderland, MA., Sinauer Associates; 2004.

5. Knapp S, Lughadha E, Paton A: Taxonomic inflation, species concepts and global species lists. TREE 2005, 20:7-8.
6. Sites J, Marshall J: Delimiting species: a Renaissance issue in systematic biology. TREE 2003, 18:462-470.

7. Hausdorf B: Progress toward a general species concept. Evolution 2011, 65:923-931.

8. Mayden R, Claridge M, Dawah H, MR W: A hierarchy of species concepts: the denouement in the saga of the species problem. In Species: The Units of Biodiversity. Edited by: MF Claridge, AH Dawah, Wilson MR. London: Chapman and HAll; 1997:381-424.

9. Hey J: On the failure of modern species concepts. TREE 2006, 21:447-450.

10. Sites J Jr, Marshall J: Operational criteria for delimiting species. Annu Rev Ecol Evol Syst 2004, 35:199-227.

11. Wiens J, Penkrot T: Delimiting species using DNA and morphological variation and discordant species limits in spiny lizards (Sceloporus). Syst Biol 2002, 51:69-91.

12. de Queiroz K: Ernst Mayr and the modern concept of species. PNAS 2005, 102:6600-6607.

13. Frost $D$, Kluge A: A consideration of epistemology in systematic biology, with special reference to species. Clad 1994, 10:259-294.

14. Mayr E: What is a species, and what is not? Philosophy of Science. 1996, 63(2):262-277.

15. Dayrat B: Towards integrative taxonomy. Biol J Linn Soc 2005, 85:407-415.

16. de Queiroz K: Different species problems and their resolution. BioEss 2005, 27:1263-1269.

17. Payne R, Sorenson M: Integrative systematics at the species level: plumage, songs and molecular phylogeny of quailfinches Ortygospiza. Bull B O C 2007, 127:4-26.

18. Sanders K, Malhotra A, Thorpe R: Combining molecular, morphological and ecological data to infer species boundaries in a cryptic tropical pitviper. Biol J Linn Soc 2006, 87:343-364.

19. Thalmann U: Biodiversity, phylogeography, biogeography and conservation: Lemurs as an example. Fol Primatol 2007, 78:420-443.

20. Avise J: What is the field of biogeography, and where is it going? TAXON 2004, 53:893-898.

21. Tattersall I: Madagascar's lemurs: Cryptic diversity or taxonomic inflation? Evol Anthropol 2007, 16:12-23.

22. Mittermeier R, Louis E Jr, Richardson M, Schwitzer C, Langrand O, Rylands AB, Hawkins F, Rajaobelina S, Ratsimbazafy J, Rasoloarison R, Roos C, Kappeler PM, Mackinnon J: Lemurs of Madagascar. Arlington, Conservation International 2010

23. Groeneveld LF, Blanco MB, Raharison J-L, Rahalinarivo V, Rasoloarison RM, Kappeler PM, Godfrey LR, Irwin MT: MtDNA and nDNA corroborate existence of sympatric dwarf lemur species at Tsinjoarivo, eastern Madagascar. Mol Phyl Evol 2010, 55:833-845.

24. Groeneveld LF, Weisrock DW, Rasoloarison RM, Yoder AD, Kappeler PM: Species delimitation in lemurs: multiple genetic loci reveal low levels of species diversity in the genus Cheirogaleus. BMC Evol Biol 2009, 9:30.

25. Weisrock D, Rasoloarison R, Fiorentino I: Delimiting Species without Nuclear Monophyly in Madagascar's Mouse Lemurs. PLOS One 2010, 5:1-13.

26. Rasoloarison R, Goodman S, Ganzhorn J: Taxonomic revision of mouse lemurs (Microcebus) in the western portions of Madagascar. Int $J$ Primatol 2000, 1.963-1019.

27. Yoder A, Rasoloarison R, Goodman S, Irwin J, Atsalis S, Ravosa M, Ganzhorn JU: Remarkable species diversity in Malagasy mouse lemurs (Primates, Microcebus). PNAS 2000, 97(21):11325-11330.

28. Zimmermann E, Cepok S, Rakotoarison N, Zietemann V, Radespiel U: Sympatric mouse lemurs in north-west Madagascar: a new rufous mouse lemur species (Microcebus ravelobensis). Folia Primatol (Basel) 1998, 69(2):106-114.

29. Andriantompohavana R, Lei R, Zaonarivelo JR, Engberg SE, Nalanirina G, McGuire SM, Andrianasolo J, Herrington K: Molecular phylogeny and taxonomic revision of the Woolly Lemurs, genus Avahi (Primates: Lemuriformes). Special publications of the Museum of Texas Tech University; 2007:51:1-59.

30. Louis E, Coles M, Andriantompohavana R, Sommer J, Engberg S, Zaonarivelo J, Mayor M, Brenneman R: Revision of the mouse lemurs (Microcebus) of eastern Madagascar. Int J Primatol 2006, 27:347-389.

31. Louis E, Engberg S, Lei R, Geng H, Sommer J: Molecular and morphological analyses of the sportive lemurs (Family Megaladapidae: Genus Lepilemur) reveals 11 previously unrecognized species. Museum of Texas Tech University 2006, 49:1-47. 
32. Davis J, Nixon K: Populations, genetic variation, and the delimitation of phylogenetic species. Syst Biol 1992, 41:421.

33. Hebert $P$, Ratnasingham $S$, de Waard J: Barcoding animal life: cytochrome C oxidase subunit 1 divergences among closely related species. Proc $R$ Soc Lond B (Suppl) 2003, 270:96-99.

34. Olivieri G, Zimmermann E, Randrianambinina B, Rasoloharijaona S, Rakotondravony D, Guschanski K, Radespiel U: The ever-increasing diversity in mouse lemurs: three new species in north and northwestern Madagascar. Mol Phyl Evol 2007, 43:309-327.

35. Craul M, Zimmermann E, Rasoloharijaona S: Unexpected species diversity of Malagasy primates (Lepilemur spp.) in the same biogeographical zone: a morphological and molecular approach with the description of two new species. BMC Evol Biol 2007, 7:83.

36. Louis E, Engberg S, McGuire S, Randriamampionona R: Revision of the mouse lemurs, Microcebus (Primates, Lemuriformes), of northern and northwestern Madagascar with descriptions of two new species at Montagne d'Ambre National Park and Antafondro classified forest. Prim Cons 2008, 23:19-38.

37. Fredsted T, Pertoldi C, Olesen J, Eberle M, Kappeler P: Microgeographic heterogeneity in spatial distribution and mtDNA variability of gray mouse lemurs (Microcebus murinus, Primates: Cheirogaleidae). Behav Ecol Sociobiol 2004, 56:393-403.

38. Walsh PD: Sample size for the diagnosis of conservation units. Conserv Biol 2000, 14:1533-1537.

39. Wiens J, Servedio M: Species delimitation in systematics: inferring diagnostic differences between species. Proc R Soc Lond B 2000, 267:631-636.

40. Pastorini J, Forstner M, Martin R: Relatiomships among Brown Lemurs (Eulemur fulvus) Based on Mitochondrial DNA Sequences. Mol Phyl Evol 2000, 16:418-429.

41. Funk D, Omland K: Species level paraphyly and polyphyly: Frequency, causes, and consequences, with insights from animal mitochondrial DNA. Ann Rev Ecol Evol Sys 2003, 34:397-423.

42. Lei R, Engberg S, Andriantompohavana R, McGuire S, Mittermeier R, Zaonarivelo J, Brenneman R, Louis E: Nocturnal lemur diversity at Masoala national park. Special Publications, Museum of Texas University 2008, 1-41.

43. Fausser J, Prosper P, Donati G, Ramanamanjato J, Rumpler Y: Phylogenetic relationships between Hapalemur species and subspecies based on mitochondrial DNA sequences. BMC Evol Biol 2002, 2:4.

44. Rabarivola C, Prosper P, Zaramody A, Andriaholinirina N: Cytogenetics and taxonomy of the genus Hapalemur. Lemur News 2007, 12:46-49.

45. Zinner D, Roos C, Fausser J: Disputed taxonomy classification of sportive lemurs (Lepilemur) in NW Madagascar. Lemur News 2007, 12:53-56.

46. Cognato A: Standard percent DNA sequence difference for insects does not predict species boundaries. J Econom Entomol 2006, 99:1037-1045.

47. Kelly RP, SARKAR IN, EERNISSE DJ, Desalle R: DNA barcoding using chitons (genus Mopalia). Mol Ecol Notes 2007, 7:177-183.

48. Sarkar IN, Planet PJ, DeSalle R: CAOS Software for use in character based DNA barcoding.[https://darchive.mblwhoilibrary.org/bitstream/handle/1912/ 2635/Sarkar_CAOS_manus3_FINAL.pdf].

49. Fredsted T, Pertoldi C, Schierup M, Kappeler P: Microsatellite analyses reveal fine-scale genetic structure in grey mouse lemurs (Microcebus murinus). Mol Ecol 2005, 14:2363-2372.

50. Petit RJ, Excoffier L: Gene flow and species delimitation. TREE 2009, 24:386-393.

51. Carstens B, Knowles L: Estimating species phylogeny from gene-tree probabilities despite incomplete lineage sorting: an example from Melanoplus grasshoppers. Syst Biol 2007, 56:400-411.

52. Edwards S, Beerli P: Perspective: gene divergence, population divergence, and the variance in coalescence time in phylogeographic studies. Evol 2000, 54:1839-1854.

53. Nichols R: Gene trees and species trees are not the same. TREE 2001, 16:358-364.

54. Riddle BR, Dawson MN, Hadly EA, Hafner DJ, Hickerson MJ, Mantooth SJ, Yoder AD: The role of molecular genetics in sculpting the future of integrative biogeography. Prog Phys Geog 2008, 32:173-202.

55. Thalmann O, Fischer A, Lankester F, Paabo S, Vigilant L: The complex evolutionary history of gorillas: insights from genomic data. Mol Biol Evol 2007, 24:146.

56. Fischer A: Evidence for a complex demographic history of Chimpanzees. Mol Biol Evol 2004, 21:799-808.
57. Fischer A, Pollack J, Thalmann O, Nickel B, Pääbo S: Demographic history and genetic differentiation in apes. Cur Biol 2006, 16:1133-1138.

58. Hey J, Nielsen R: Multilocus methods for estimating population sizes, migration rates and divergence time, with applications to the divergence of Drosophila pseudoobscura and D. persimilis. Genet 2004, 167:747-760

59. Brumfield R, Beerli P, Nickerson D, Edwards S: The utility of single nucleotide polymorphisms in inferences of population history. TREE 2003, 18:249-256.

60. Hewitt G: Speciation, hybrid zones and phylogeography-or seeing genes in space and time. Mol Ecol 2001, 10:537-549.

61. Horvath J, Weisrock D, Embry S, Fiorentino I, Balhoff J, Kappeler P, Wray G, Willard H, Yoder A: Development and application of a phylogenomic toolkit: Resolving the evolutionary history of Madagascar's lemurs. Gen Res 2008, 18:489-499.

62. Beaumont M, Rannala B: The Bayesian revolution in genetics. Nat Rev Genet 2004, 5:251-261.

63. Brito $P$, Edwards S: Multilocus phylogeography and phylogenetics using sequence-based markers. Genet 2008, 1-17.

64. Pritchard J, Stephens M, Donnelly P: Inference of population structure using multilocus genotype data. Genet 2000, 155:945.

65. Cummings MP, Neel MC, Shaw KL: A genelogical approach to quantifying lineage divergence. Evol 2008, 62:2411-2422.

66. Rach J, Desalle R, Sarkar I, Schierwater B, Hadrys H: Character-based DNA barcoding allows discrimination of genera, species and populations in Odonata. Proc R Soc Lond B 2008, 275:237.

67. Seppä $P$, Helanterä $H$, Trontti K, Puntilla $P$, Chernenko A, Sundström L: The many ways to delimit species: hairs, genes and surface chemistry. Myrmelcol News 2011, 15:31-41.

68. Alstrom P, Rasmussen P, Olsson U, Sundberg P: Species delimitation based on multiple criteria: the Spotted Bush Warbler Bradypterus thoracicus complex (Aves:Megaluridae). Zool J Linn Soc Lond 2008, 154:291-307.

69. Zimmermann E, Vorobieva E, Wrogemann D: Use of vocal fingerprinting for specific discrimination of gray (Microcebus murinus) and rufous mouse lemurs (Microcebus rufus). Int J Primatol 2000, 21(5):837-852.

70. Nietsch A, Kopp M: Role of vocalization in species differentiation of Sulawesi tarsiers. Folia Primatol 2000, 69(Suppl 1):371-378.

71. Groves C, Shekelle M: The Genera and Species of Tarsiidae. Int J Primatol 2010, 31(6):1071-1082.

72. Tamura K, Dudley J, Nei M, Kumar S: MEGA4: Molecular Evolutionary Genetics Analysis (MEGA) software version 4.0. Mol Biol Evol 2007, 24:1596-1599.

doi:10.1186/1471-2148-11-216

Cite this article as: Markolf et al:: On species delimitation: Yet another lemur species or just genetic variation? BMC Evolutionary Biology 2011 $11: 216$

\section{Submit your next manuscript to BioMed Central and take full advantage of:}

- Convenient online submission

- Thorough peer review

- No space constraints or color figure charges

- Immediate publication on acceptance

- Inclusion in PubMed, CAS, Scopus and Google Scholar

- Research which is freely available for redistribution

Submit your manuscript at www.biomedcentral.com/submit
C Biomed Central 